\title{
Mechanical demands of the two-handed hardstyle kettlebell swing in novice older adults: an exploratory profile
}

\author{
Neil J. Meigh ${ }^{1}$, Wayne A. Hing ${ }^{1}$, Ben Schram ${ }^{1}$, Justin W.L. Keogh ${ }^{1,2,3}$ \\ ${ }^{1}$ Faculty of Health Sciences and Medicine, Bond University, Gold Coast, Queensland, Australia \\ ${ }^{2}$ Sports Performance Research Centre New Zealand, AUT University, Auckland, New Zealand \\ ${ }^{3}$ Kasturba Medical College, Manipal Academy of Higher Education. Mangalore, Manipal, Karnataka, India \\ Corresponding Author: \\ Neil Meigh ${ }^{1}$ \\ Bond Institute of Health \& Sport, 2 Promethean Way, Robina, QLD, 4226, Australia \\ Email address: nmeigh@bond.edu.au
}

\begin{abstract}
Background. Understanding the mechanical demands of an exercise and its' technique increases clinical confidence when assessing the benefits and risks of a prescribed exercise. This study profiles the mechanical demands of the hardstyle kettlebell swing in novice older adults and compares peak force with kettlebell deadlifts. These data will help therapists choose the most appropriate kettlebell exercise (deadlifts or swings) and weights for progressing kettlebell training for older adults.

Methods. Thirty-five insufficiently physically active, community-dwelling males and females (59-79 years) were recruited. Two-handed hardstyle swings were performed with 8-16 kg and deadlifts with 8-24 kg and 8-32 kg for females and males, respectively. Ground reaction forces (GRFs) were obtained from a floor-mounted force platform. Force-time curves (FTCs), peak force, forward force relative to vertical force, rate of force development (RFD), and swing cadence were investigated. Peak GRF was compared by exercise and by sex, with RFD reported for swings.

Results. For kettlebells weights up to $16 \mathrm{~kg}$, paired samples T-tests show a large exercise effect $(\delta>1.4)$ with peak force significantly higher for swings than deadlifts. Data shows: (i) significantly higher peak force during swings than deadlifts $(\delta=1.77)$, reaching $4.5(1.0) \mathrm{N} . \mathrm{kg}^{-1}$, (ii) peak force during an $8 \mathrm{~kg}$ swing was greater than a $32 \mathrm{~kg}$ deadlift, (iii) no significant difference in normalised peak force between males and females performing kettlebell swings, but a moderately large effect size during deadlifts (males $>$ females, $\delta=0.69$ ), (iv) mean RFD of $19.9(4.7) \mathrm{N}^{-1} \mathrm{~s}^{-1} \mathrm{~kg}^{-1}$ with a very weak, positive correlation with kettlebell weight $(y=14.4+0.32 x)$, and trivial or non-significant effect of sex, (v) mean forward force equal to $5.5 \%$ of vertical force during swings, increasing from 3.8 (1.6) $\%$ with $8 \mathrm{~kg}$ to 7.1 (2.6) $\%$ with $16 \mathrm{~kg}$.

Conclusion. Where GRF is a therapeutic target, kettlebell swings with an $8 \mathrm{~kg}$ kettlebell could have similar effects to much heavier deadlifts $(>24 \mathrm{~kg})$. Compared to kettlebell deadlifts, the performance of kettlebell swings may be an easier, more convenient, and more appealing option for older adults in a primary care setting or at home. The hardstyle swing with $8 \mathrm{~kg}$ has the potential to produce double bodyweight in GRF and might be a suitable exercise to improve lower limb RFD and physical function in older adults. Findings from this study were used to inform the BELL Trial, a pragmatic clinical trial of kettlebell training with older adults. www.anzctr.org.au ACTRN12619001177145.
\end{abstract}

\section{Introduction}

Clinical trials of kettlebell training with older adults are limited, but results have been encouraging ${ }^{(1,2)}$. Small and portable, kettlebells have been recommended for their ease of use, affordability, and for being less intimidating than other equipment ${ }^{(3)}$. These are attractive features for clinicians and researchers who have used kettlebells in rehabilitative programs for older individuals with hip fracture ${ }^{(4)}$ sarcopenia $^{(1)}$ and Parkinson's disease ${ }^{(2)}$.

An important component of therapeutic exercise is the choice of load and knowledge of resultant force acting on the 
body and its tissues. A successful clinical outcome of therapeutic exercise may depend upon the correct manipulation of force to stimulate a desired adaptative response in a target tissue ${ }^{(5)}$. In older adults, repetitive loading is used in the management of hip and knee arthritis, back pain, and osteoporosis ${ }^{(6,7)}$. Healthcare providers must first do no harm, which necessitates avoiding exposure to inappropriate volume, intensity, or load, which may result in acute injury, excessive muscle soreness, or irritate an already painful condition such as osteoarthritis. Understanding the magnitude of force acting on the body during these exercises is therefore a necessary starting point.

For an older population, GRF and RFD are important measures of functional decline ${ }^{(8,9)}$. Ground reaction force is associated with strength and power at the hip and knee ${ }^{(10)}$, gait speed ${ }^{(9)}$, falls risk ${ }^{(11)}$, and may be a better predictor of functional decline than both grip strength ${ }^{(8)}$ and the five-times Sit-to-Stand test ${ }^{(10)}$. Movement patterns observed in a Sit-To-Stand, floor transfer, and reaching overhead, are also seen in kettlebell training; the most widely recognised type being the 'hardstyle' swing introduced by Pavel Tsatsouline ${ }^{(12)}$. A hardstyle swing is believed to improve lower limb power and by association, the ability to apply GRF, therefore, the kettlebell swing might positively influence lower limb function in older adults, reduce risk of falls, and be an ideal tool to promote healthy aging ${ }^{(13)}$.

A recent review ${ }^{(13)}$ identified no standards or guidelines to inform healthcare providers of how to use kettlebells safely and confidently with older adults. Additionally, current resistance training guidelines for older adults ${ }^{(14-16)}$ do not translate to hardstyle kettlebell practices. Kettlebell weights are not chosen based on a percentage of ' 1 repetition maximum', and simply adding a kettlebell to an exercise ${ }^{(4)}$ is not representative of 'kettlebell training'. It is a safety concern for providers wanting to prescribe a ballistic, free-weight resistance training program for older adults, without guidelines and for which the mechanical demands, acute responses, and risks are unknown.

Hardstyle literature suggests that outcomes are dependent upon technique ${ }^{(12,17)}$. Kinematic differences between novice and expert have been described ${ }^{(18)}$ with significant, large effect size differences in GRF between novice and instructor (19), however, these data are from healthy young adults. Data from young active populations are informative and provide important reference points ${ }^{(20-25)}$, but these cannot be generalised to older adults, especially those who are sedentary, insufficiently active or living with chronic health conditions. Without population-specific data, healthcare providers are just as likely to over-dose as under-dose the person in their care, potentially causing harm, or having no positive effect at all. A profile of the kettlebell swing and kettlebell deadlift in older adults is therefore warranted.

Therefore, the primary aim of this study was to profile the mechanical demands (GRF, RFD, forward force, and swing cadence) of the 2-handed hardstyle kettlebell swing in novice older adults. A secondary aim of this study was to provide context for the GRF of a hardstyle swing by comparing it to a kettlebell deadlift. These data were used to inform exercise prescription for the BELL trial (www.anzctr.org.au ACTRN12619001177145).

\section{Materials \& Methods \\ Participants.}

A total of 17 males and 18 females aged 58-79 years were recruited. None of the participants had previously used kettlebells. Thirty-two identified as sedentary, not having engaged in a structured exercise program for at least nine months, and few had experience with commercial resistance equipment. Participants were free from injury and did not disclose any health or medical conditions considered to be a high risk ${ }^{(26)}$. After a thorough explanation of the study aims, protocols, and potential risks, participants provided written informed consent. Ethical approval for this study was granted by Bond University Human Research Ethics Committee (NM03279).

\section{Protocol}

Data were collected from the University biomechanics laboratory, each participant attending two 1-hour sessions on consecutive weeks. Two-handed kettlebell swings to chest-height were performed on a floor-mounted force flatform (AMTI, Watertown, NY, USA) recording GRF at $1000 \mathrm{~Hz}$ using NetForce software (AMTI, USA). Participant body mass was captured by the force plate from a period of quiet standing. Tri-plantar force variables were obtained from 
the floor-mounted force platform. The variables of interest were peak GRF, dynamic RFD, and swing cadence. Participants performed a single set of 12 repetitions with each kettlebell, with the middle 10 repetitions used for analysis. A custom program (Microsoft Excel, Version 2012) was used to calculate peak force during each swing cycle of the set, with values manually assessed and verified against the corresponding FTC. To obtain peak net force, system weight (body mass + kettlebell weight) was subtracted from the square root of squared and summed data:

$$
\sqrt{F_{z}^{2}+F_{x}^{2}+F_{y}^{2}}\left(\mathrm{~F}_{\mathrm{z}}=\text { vertical force, } \mathrm{F}_{\mathrm{y}}=\text { horizontal forward force, } \mathrm{F}_{\mathrm{x}}=\text { medio-lateral force }\right) \text {. }
$$

The back or bottom position of the swing was used as the start of each swing cycle. Dynamic RFD (N.s s $^{-1}$ ) during hip extension (propulsion) was calculated as the change in resultant GRF during Phase 1, divided by elapsed time and normalised to body mass $\left(\mathrm{N} . \mathrm{s}^{-1} \cdot \mathrm{kg}^{-1}\right)$, with this reported as the mean of 10 swings. Cadence in swings per minute (SPM) was calculated from the average time between peak force of hip extension in each swing cycle. Peak force was reported as resultant force unless stated otherwise.
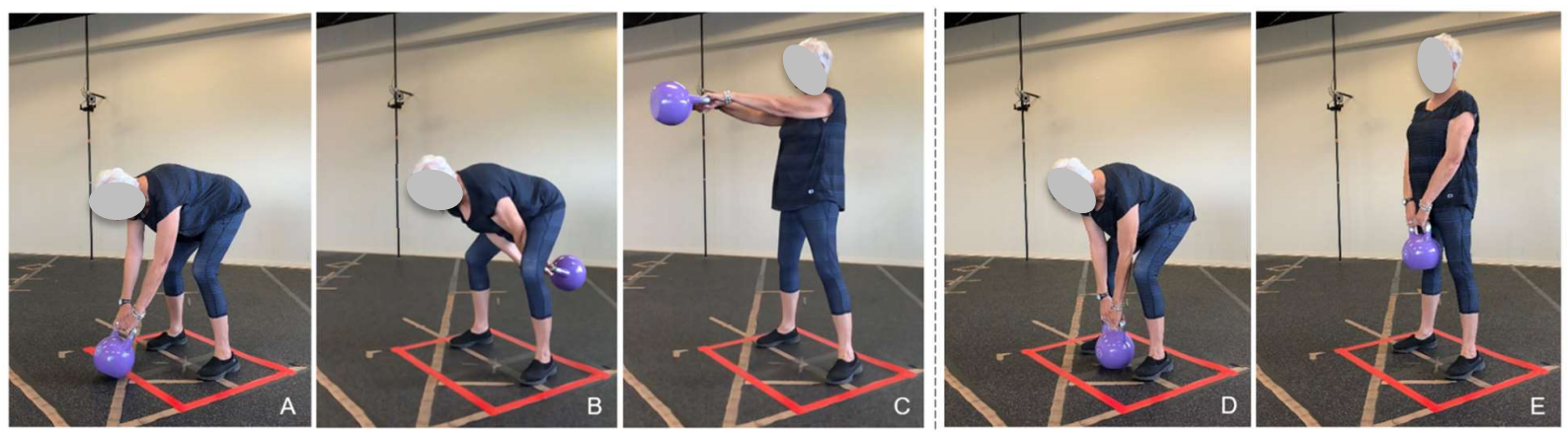

Figure 1. Key positions during the two-handed hardstyle kettlebell swing and kettlebell deadlift: dead-start / dead-stop for a swing (A), start and end position of single swing cycle (B), mid-swing (C), dead-start for a kettlebell deadlift (D), top position of the deadlift. Red tape marks the boundary of the force platform (E).

\section{Procedure.}

During the first session, participants received instruction on how to perform the hardstyle swing as previously described ${ }^{(19,27)}$. The following drills served as a warm-up; (1) unloaded hip-hinge - standing at a distance roughly equal to the length of their foot away from a wall, participants used the wall as an external focus of attention (target for their buttocks to touch) to practice the 'hinge' movement, before returning to an upright position. (2) performing the 4 phases of a swing cycle ${ }^{(19)}$ without weight, led by the instructor to a 4-count. (3) double knee extension swings ${ }^{(28)}$ with $8 \mathrm{~kg}$ to familiarise themselves with the external load, bell movement through the legs, and weight shift. (4) towel-swings ${ }^{(12)}$ with 4-8 kg to differentiate a 'swing' from a 'lift' and (5) two to three sets of instructor-led swings performed at cadence of approximately 40 SPM, to illustrate the intended ballistic nature of the hardstyle swing.

Force USA competition kettlebells from 8-32 kg of standardised dimensions were used, increasing in $2 \mathrm{~kg}$ increments to $24 \mathrm{~kg}$, then $4 \mathrm{~kg}$ increments to $32 \mathrm{~kg}$. Target weights for swings and deadlifts were pre-selected based on the lead investigator's experience as a kettlebell instructor; $12 \mathrm{~kg}$ and $24 \mathrm{~kg}$ for females, and $16 \mathrm{~kg}$ and $32 \mathrm{~kg}$ for males, respectively. Sets of swings began and ended in a 'dead-start' position (Fig. 1A). Females were given the opportunity to swing $14 \mathrm{~kg}$ if their $12 \mathrm{~kg}$ swing was performed confidently with acceptable technique. Males were not given the opportunity to swing heavier than $16 \mathrm{~kg}$. An ideal hardstyle swing pattern was not required or expected. Deadlifts were performed with feet positioned either side of the bell (Fig. 1D) as previously described ${ }^{(29)}$. Only peak resultant force was analysed for deadlifts.

\section{Statistical analyses.}

Descriptive statistics were reported for normally distributed continuous variables. Measures of centrality and dispersion are presented as mean (SD) and verified for normality using box-plots, histograms, and Shapiro-Wilk tests. 
Differences between males and females, swings and deadlifts, were analysed using independent samples T-tests and paired samples T-tests, respectively, subject to the sampling distribution being normal for each group. Mean Difference (MD) is presented with $95 \%$ confidence interval (CI). Effect sizes were calculated and interpreted using Lenhard and Lenhard ${ }^{(30)}$ and Magnusson ${ }^{(31)}$, quantified as trivial, small, moderate, large, very large, and extremely large where effect size $<0.20,0.20-0.59,0.60-1.19,1.20-1.99,2.0-3.99$ and $\geq 4.0$ respectively ${ }^{(32)}$. Probability of superiority has been used to illustrate the Cohen's d effect size, representing the chance that a person from group A will have a higher score than a person picked at random from group $\mathrm{B}^{(31)}$. The relationships between peak net ground reaction force and kettlebell weight for swings and deadlifts, and RFD and kettlebell weight during swings, were investigated using simple linear regression. Preliminary analyses were performed to ensure no violation of the assumptions of normality, linearity and homoscedasticity. Statistical analyses were performed using SPSS (version 26.0; SPSS Inc., Chicago, IL, USA), and $p<0.05$ was used to indicate statistical significance.

\section{Results}

Participant demographics are presented in Table 1. All females performed swings with 8-12 $\mathrm{kg}$ kettlebells. Nine females swung $14 \mathrm{~kg}$ and two swung $16 \mathrm{~kg}$. All males performed swings with 8-12 kg. Sixteen males swung $14 \mathrm{~kg}$ and 15 swung $16 \mathrm{~kg}$.

Table 1. Participant characteristics

\begin{tabular}{lrr}
\hline Characteristic & Older Males & Older Females \\
\hline Number & 17 & 18 \\
Age (years) & $68.5(4.2)$ & $68.1(4.0)$ \\
Height $(\mathrm{cm})$ & $176.8(7.8)$ & $163.9(5.4)$ \\
Weight $(\mathrm{kg})$ & $90.2(14.9)$ & $71.7(11.5)$ \\
BMI $\left(\mathrm{kg} / \mathrm{m}^{2}\right)$ & $29.1(2.5)$ & $26.6(4.5)$ \\
\hline Data are presented as mean $(S D)$, unless otherwise specified.
\end{tabular}

\section{Peak net ground reaction force.}

There was a large $(\delta=1.77)$ significant difference in peak force between the kettlebell swing and kettlebell deadlift (Fig. 2 and Table 2), with the mean probability of superiority for the kettlebell swing across loads of 8-16 kg being $89.5 \%$. The relationship between peak force and kettlebell weight was investigated. In both cases, there was a very weak $(r<0.30)$ positive correlation between the two variables. Regression coefficients to predict peak force where $x$ $=$ kettlebell mass in $\mathrm{kg}$.

Peak force - swing

Peak force - deadlift

$$
\begin{aligned}
& \mathrm{y}=3.10+0.11 x(r=0.26, p=0.001, \text { CI }[0.05,0.81]) \\
& \mathrm{y}=2.63+0.02 x,(r=0.19, p=0.001, \text { CI }[0.01,0.03])
\end{aligned}
$$




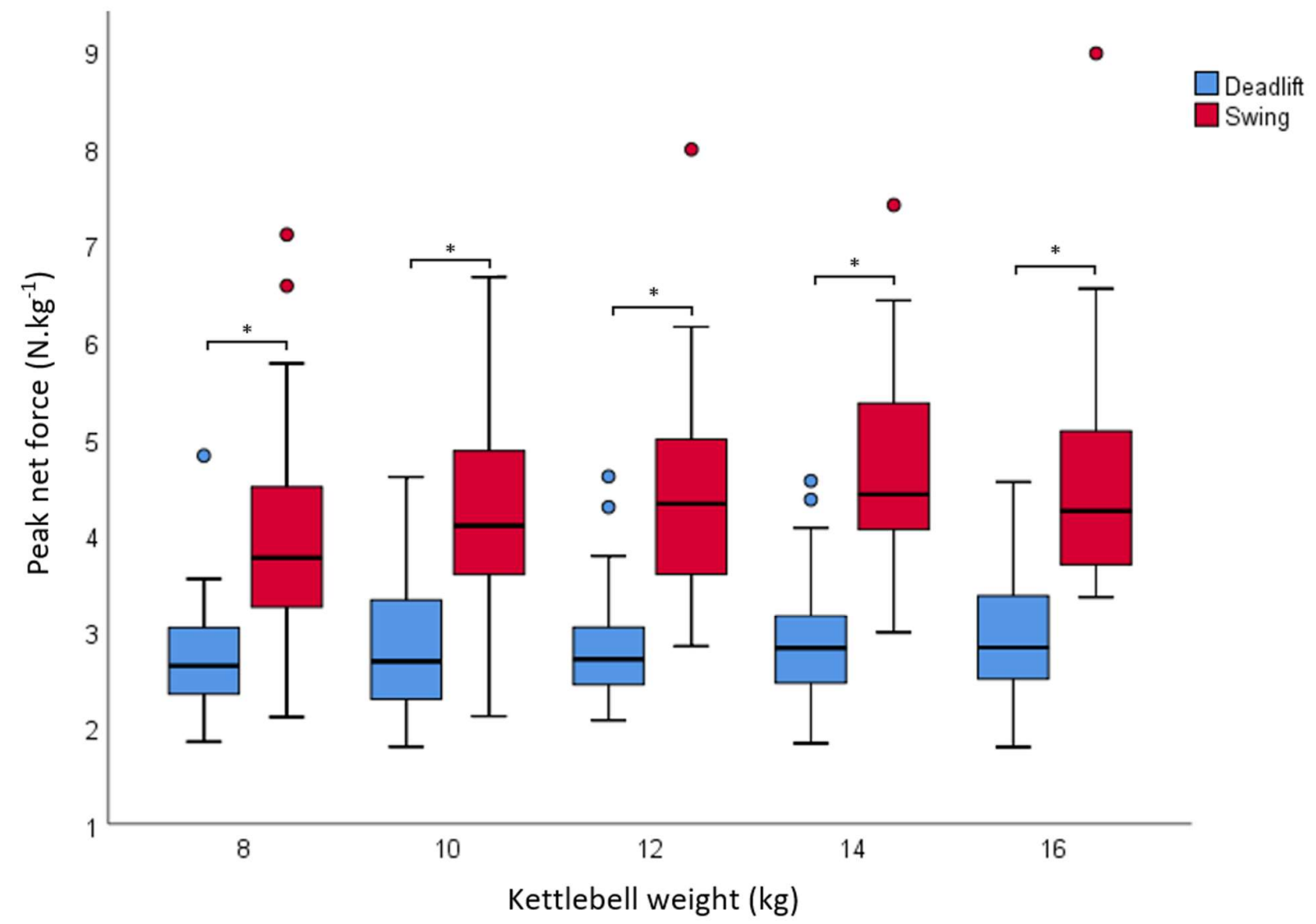

Figure 2. Box-and-whisker plot of large significant difference in peak net ground reaction force between kettlebell swings and deadlifts Box represents median observations (horizontal rule) with 25th and 75th percentiles of observed data (top of bottom of box). Length of each whisker is 1.5 times interquartile range. Data points that are more than 1.5 $\mathrm{x}$ interquartile range are represented by "o" (Tukey's outlier detection method). $*=p<0.05$

Tables 2. Peak net ground reaction force for swings and deadlifts $\left(\mathrm{N}_{\mathrm{kg}} \mathrm{kg}^{-1}\right)$

\begin{tabular}{|c|c|c|c|c|c|c|c|}
\hline \multirow{2}{*}{$\begin{array}{c}\text { KB } \\
\text { weight } \\
(\mathrm{kg}) \\
\end{array}$} & \multicolumn{2}{|c|}{ Mean (SD) } & \multirow[b]{2}{*}{$\operatorname{MD}(95 \% \mathrm{CI})$} & \multirow[b]{2}{*}{$t$} & \multirow[b]{2}{*}{$p$} & \multicolumn{2}{|r|}{ Cohen's } \\
\hline & Swing & Deadlift & & & & $\delta$ & $\begin{array}{c}\text { Probability of } \\
\text { superiority (\%) }\end{array}$ \\
\hline 8 & $3.9(1.0)$ & $2.8(0.6)$ & $1.2(0.8,1.6)$ & $29(6.110)$ & $<0.001$ & 1.42 & 84.2 \\
\hline 10 & $4.3(1.0)$ & $2.8(0.7)$ & $1.5(1.2,1.9)$ & $29(9.408)$ & $<0.001$ & 1.76 & 89.3 \\
\hline 12 & $4.4(0.8)$ & $2.8(0.6)$ & $1.5(1.2,1.9)$ & $29(9.927)$ & $<0.001$ & 1.99 & 92.0 \\
\hline 14 & $4.7(1.0)$ & $3.0(0.6)$ & $1.7(1.3,2.1)$ & $22(8.887)$ & $<0.001$ & 2.00 & 92.1 \\
\hline 16 & $4.5(1.0)$ & $3.1(0.6)$ & $1.4(0.8,2.0)$ & $15(5.067)$ & $<0.001$ & 1.68 & 88.3 \\
\hline
\end{tabular}

Only trivial-to-small non-significant effects were found between males and females performing kettlebell swings up to $16 \mathrm{~kg}$, however sex influenced peak force during kettlebell deadlifts. From 8-24 kg, peak force during deadlifts was moderately higher $(\delta=0.69)$ for males than females, with a $68.7 \%$ probability of superiority. There was a statistically significant difference between males and female using 8,12 and $14 \mathrm{~kg}$ kettlebells, with the mean probability of superiority being $71.2 \%(\delta=0.79)$ (Fig. 3 and Table 3 ). 


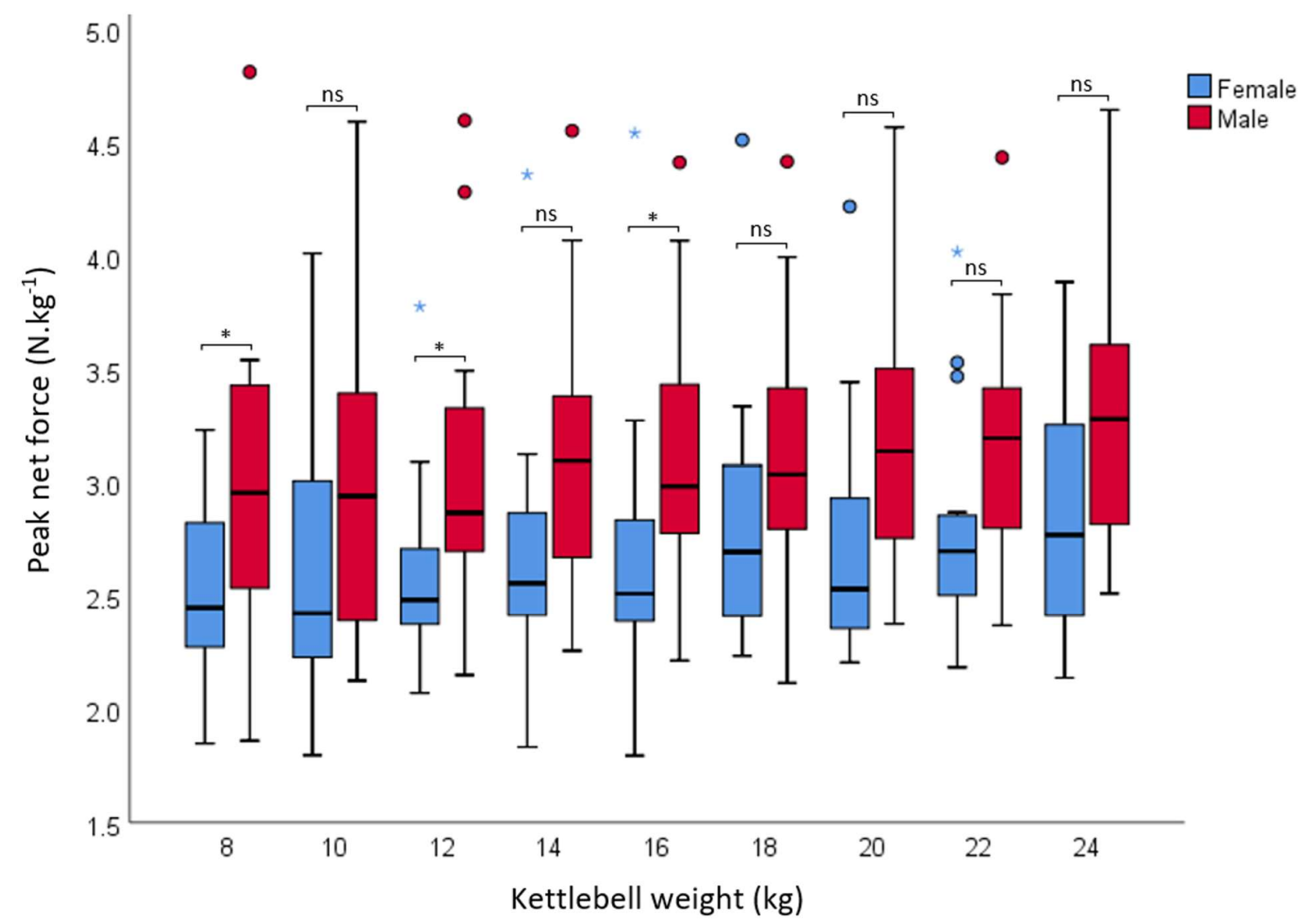

Figure 3. Moderately large effect of sex on peak force during kettlebell deadlifts with $68.7 \%$ mean probability of superiority (males $>$ females) with $8-24 \mathrm{~kg}$ kettlebells. Data points that are more than $3 \mathrm{x}$ interquartile range are represented by “约”. * $=p<0.05$, ns $=p>0.05$ 
Table 3. Peak net ground reaction force for males and females during kettlebell deadlifts $\left(\mathrm{N} \cdot \mathrm{kg}^{-1}\right)$

\begin{tabular}{|c|c|c|c|c|c|c|c|}
\hline \multirow{2}{*}{$\begin{array}{c}\mathrm{KB} \\
\text { weight } \\
(\mathrm{kg})\end{array}$} & \multicolumn{2}{|c|}{ Mean (SD) } & \multirow[b]{2}{*}{$\mathrm{MD}[95 \% \mathrm{CI}]$} & \multirow[b]{2}{*}{$t$} & \multirow[b]{2}{*}{$p$} & \multicolumn{2}{|r|}{ Cohen's } \\
\hline & Male & Female & & & & $\delta$ & $\begin{array}{c}\text { Probability of } \\
\text { superiority }(\%)\end{array}$ \\
\hline 8 & $3.0(0.7)$ & $2.5(0.4)$ & $0.4[<0.05,0.87]$ & $28(2.112)$ & 0.044 & 0.77 & 70.7 \\
\hline 10 & $3.0(0.7)$ & $2.6(0.6)$ & $0.3[-0.2,0.8]$ & $28(1.318)$ & 0.198 & 0.48 & 63.3 \\
\hline 12 & $3.1(0.7)$ & $2.6(0.4)$ & $0.5[<0.05,0.9]$ & $28(2.242)$ & 0.033 & 0.82 & 71.9 \\
\hline 14 & $3.1(0.6)$ & $2.7(0.6)$ & $0.4[<0.05,0.9]$ & $28(1.970)$ & 0.059 & 0.72 & 69.5 \\
\hline 16 & $3.2(0.6)$ & $2.7(0.6)$ & $0.5[<0.05,0.9]$ & $28(2.114)$ & 0.044 & 0.77 & 70.7 \\
\hline 18 & $3.1(0.6)$ & $2.8(0.6)$ & $0.3[-0.1,0.7]$ & $28(1.417)$ & 0.168 & 0.52 & 64.3 \\
\hline 20 & $3.2(0.6)$ & $2.8(0.6)$ & $0.4[<0.05,0.8]$ & $28(1.899)$ & 0.068 & 0.69 & 68.7 \\
\hline 22 & $3.2(0.6)$ & $2.8(0.5)$ & $0.3[<0.05,0.7]$ & $28(1.797)$ & 0.083 & 0.66 & 68.0 \\
\hline 24 & $3.3(0.6)$ & $2.9(0.6)$ & $0.4[<0.05,0.8]$ & $28(1.861)$ & 0.073 & 0.77 & 10.7 \\
\hline 28 & $3.4(0.7)$ & $2.7(0.2)$ & $0.8[-0.3,1.8]$ & $14(1.537)$ & 0.147 & 1.16 & 79.4 \\
\hline 32 & $3.6(1.0)$ & $2.6(0.5)$ & $1.0[-0.5,2.5]$ & $12(1.408)$ & 0.184 & 1.08 & 77.7 \\
\hline
\end{tabular}

\section{Rate of force development}

Rate of force development was not significantly different between consecutive kettlebell weights. There was a significant difference $(\delta=0.5-0.7)$ in RFD between the $8 \mathrm{~kg}$ and $14 \mathrm{~kg}$ kettlebell, and the $8 \mathrm{~kg}$ and $16 \mathrm{~kg}$ kettlebell: $\mathrm{MD}=2.2(0.5,3.9), t=(24) 2.721, p=0.012$, and $\mathrm{MD}=3.89(1.59,6.20), t=(16) 3.577, p=0.003$, respectively (Fig. 4 and Table 4).

Analysis of the effect of sex on RFD revealed a significant difference between males and females, but only with $8 \mathrm{~kg}$ (Fig. 4). Except for the $n=2$ females who swung $16 \mathrm{~kg}$, paired samples analysis revealed no significant increase in RFD between the lightest and heaviest weights for males or females. The relationship between RFD and kettlebell weight was investigated. Linear regression shows a very weak, positive correlation between the two variables where $\mathrm{y}(\mathrm{RFD})=14.4+0.32 x(r=0.03, p=0.032, \mathrm{CI}[0.03,0.61])$ where $x=$ kettlebell mass in $\mathrm{kg}$. 


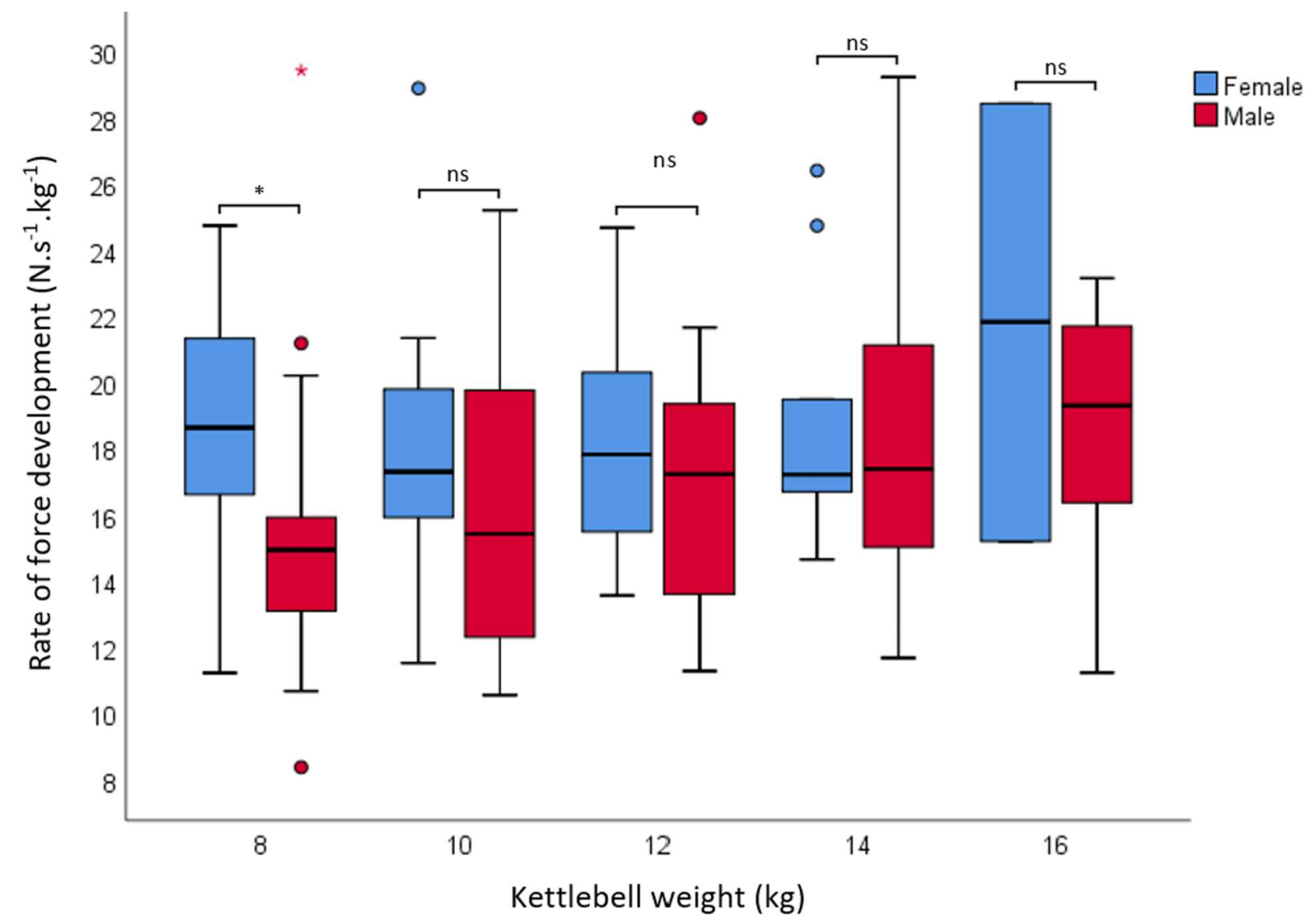

Figure 4. Trivial effect of sex on RFD. $*=p<0.05, \mathrm{~ns}=p>0.05$. One outlier at $16 \mathrm{~kg}$ and one extreme outlier at 12 $\mathrm{kg}$ not shown.

Table 4. Rate of force development during kettlebell swings for males and females $\left(\mathrm{N} \cdot \mathrm{s}^{-1} \cdot \mathrm{kg}^{-1}\right)$

\begin{tabular}{|c|c|c|c|c|c|c|c|}
\hline \multirow{2}{*}{$\begin{array}{c}\mathrm{KB} \\
\text { weight } \\
(\mathrm{kg})\end{array}$} & \multicolumn{2}{|c|}{ Mean (SD) } & \multirow{2}{*}{ MD $[95 \% \mathrm{CI}]$} & \multirow[b]{2}{*}{$t$} & \multirow[b]{2}{*}{$p$} & \multicolumn{2}{|r|}{ Cohen's } \\
\hline & Males & Females & & & & $\delta$ & $\begin{array}{c}\text { Probability of } \\
\text { superiority (\%) }\end{array}$ \\
\hline 8 & $15.5(4.9)$ & $18.7(3.6)$ & $3.3[0.3,6.6]$ & (33) 2.255 & 0.031 & 0.75 & 70.2 \\
\hline 10 & $16.7(4.7)$ & $17.8(3.7)$ & $1.1[-1.8,4.0]$ & (33) 0.776 & 0.443 & 0.26 & 57.3 \\
\hline 12 & $18.3(6.5)$ & $18.1(3.2)$ & $-0.2[-3.7,3.3]$ & (33) -0.111 & 0.913 & 0.04 & 51.1 \\
\hline 14 & $18.4(4.7)$ & $18.8(4.1)$ & $0.5[-3.4,4.3]$ & (23) 2.47 & 0.807 & 0.09 & 52.5 \\
\hline 16 & $19.3(5.2)$ & $21.8(9.3)$ & $2.5[-6.5,11.5]$ & (15) 0.560 & 0.560 & 0.45 & 62.5 \\
\hline
\end{tabular}

\section{Forward force}

Mean forward force was 0.055 (5.5\%) of the vertical GRF during the kettlebell swings. There was a small $(\delta=0.34)$ increase in the ratio of forward to vertical GRF between 8 and $16 \mathrm{~kg}, \mathrm{MD}=0.33(0.21,0.45), t=(14) 5.890, p=$ $<0.001$. The trivial to small differences between males and females were not significant at any weight (Fig. 5). Between 8 and $14 \mathrm{~kg}$, the absolute change in ratio of horizontal to vertical force was $2.5 \%$ for females, increasing from $3.7 \%$ to $6.9 \%$. For males, the absolute change was $2.6 \%$, from $3.8 \%$ with $8 \mathrm{~kg}$ to $7.3 \%$ with $16 \mathrm{~kg}$. 


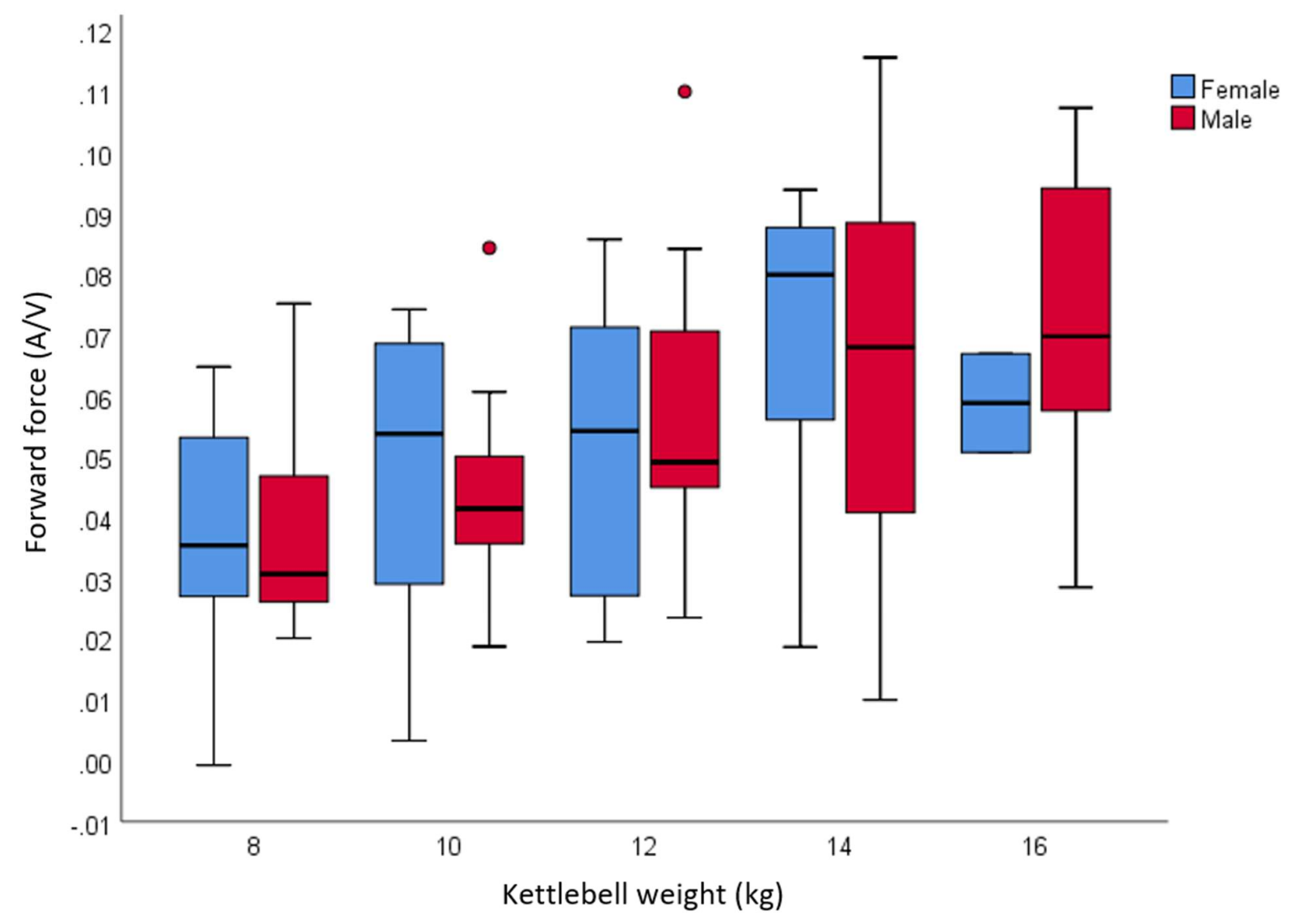

Figure 5. No significant effect of sex on small increases in forward force with increasing kettlebell weight. $\mathrm{A} / \mathrm{V}=$ ratio of anterior (forward) horizontal to vertical GRF.

\section{Cadence}

Mean swing cadence up to $16 \mathrm{~kg}$ for the kettlebell swings was 35.7 (2.3) SPM, range $=29.2$ to 41.2. There was a statistically significant difference $(p<0.05)$ in cadence between 10 and $12 \mathrm{~kg}$ and 12 and $14 \mathrm{~kg}$ swings, however, means remained between 35 and 36 SPM. The effect of sex on cadence revealed significant differences between males and females at all weights (Fig. 6). Between 8 and $16 \mathrm{~kg}$, there was a moderately large $(\delta=0.9)$ effect size, with a mean difference of 1.9 SPM and $73.8 \%$ probability of superiority (females $>$ males). 


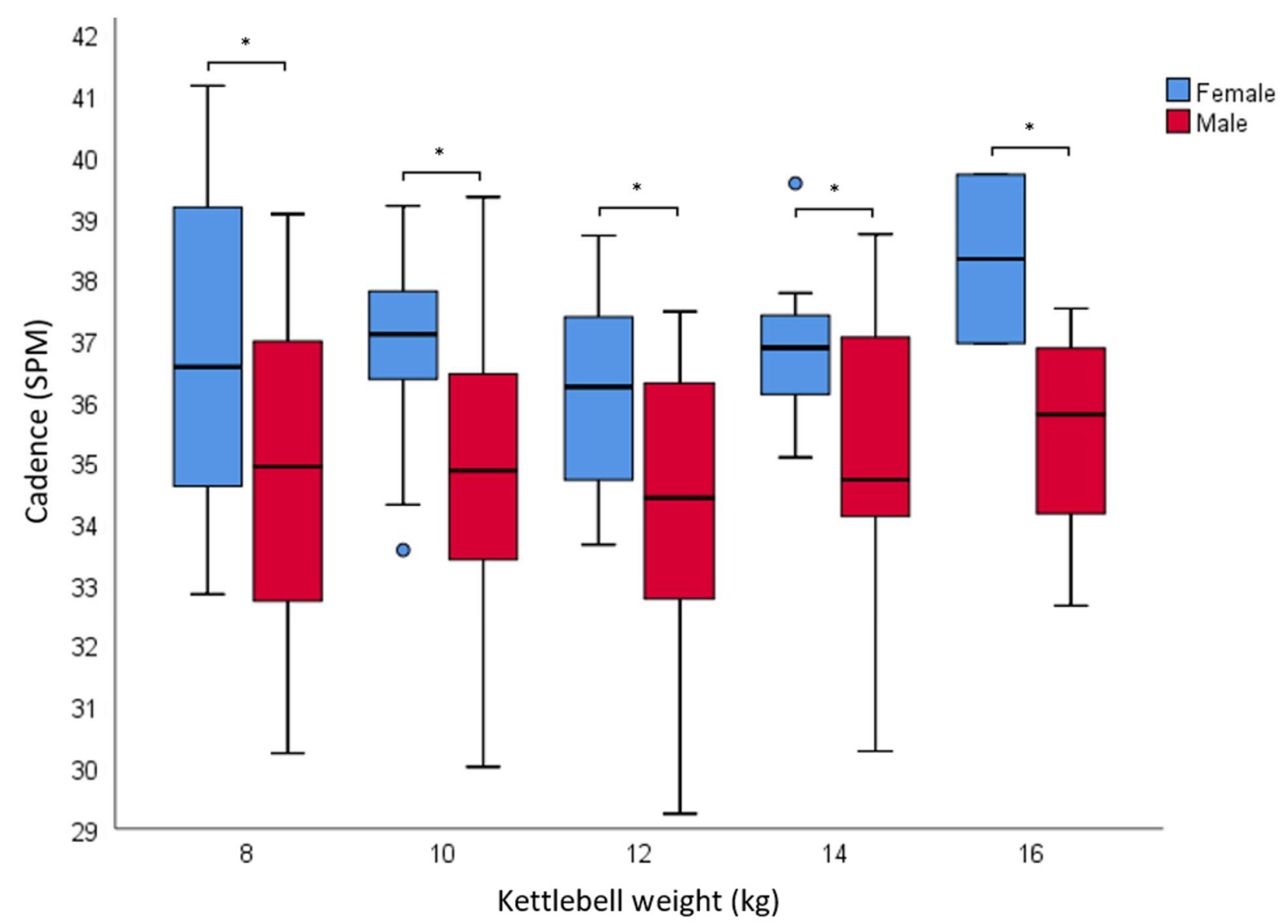

Figure 6. Moderately large effect of sex on swing cadence. SPM $=$ swings per minute. ${ }^{*}=p<0.05$

\section{Force-time curve characteristics}

Three distinct movement strategies emerged, which were inconsistent with a proficient swing ${ }^{(19)}$. 1) lifting the bell with the upper limbs, 2) a whole-body effort to perform the movement, 3) controlling the bell's decent from midswing, with little visual dissociation between upper and lower limbs, in which the body appeared to collapse downward with the bell's vertical displacement. Representative FTCs recorded from two participants which illustrate these movement strategies, are shown in Fig. 7. A double-peak (Fig. 7A) is consistent with a sequential movement, initially involving explosive hip extension, immediately followed by active shoulder flexion to lift the bell to the desired height. A wider, multi-peaked profile (Fig. 7B) is consistent with a more simultaneous movement, and lack of ballistic hip extension during propulsion. Absence of a second smaller force peak (shown in Fig. 7A) is consistent with not allowing the bell to drop from mid-swing. These profiles illustrate the effect of technique on force and cadence. The ballistic pattern more consistent with a proficient hardstyle swing (A), resulted in higher peak net force (368.2 $\mathrm{N}$ vs $257.1 \mathrm{~N})$, higher force as a percentage of bodyweight $(47.5 \% \mathrm{vs} 33.8 \%$ ), a larger proportion of horizontal forward force $(6.8 \%$ vs $2.9 \%$ ), and faster swing cadence (36.4 SPM vs 34.1 SPM). 

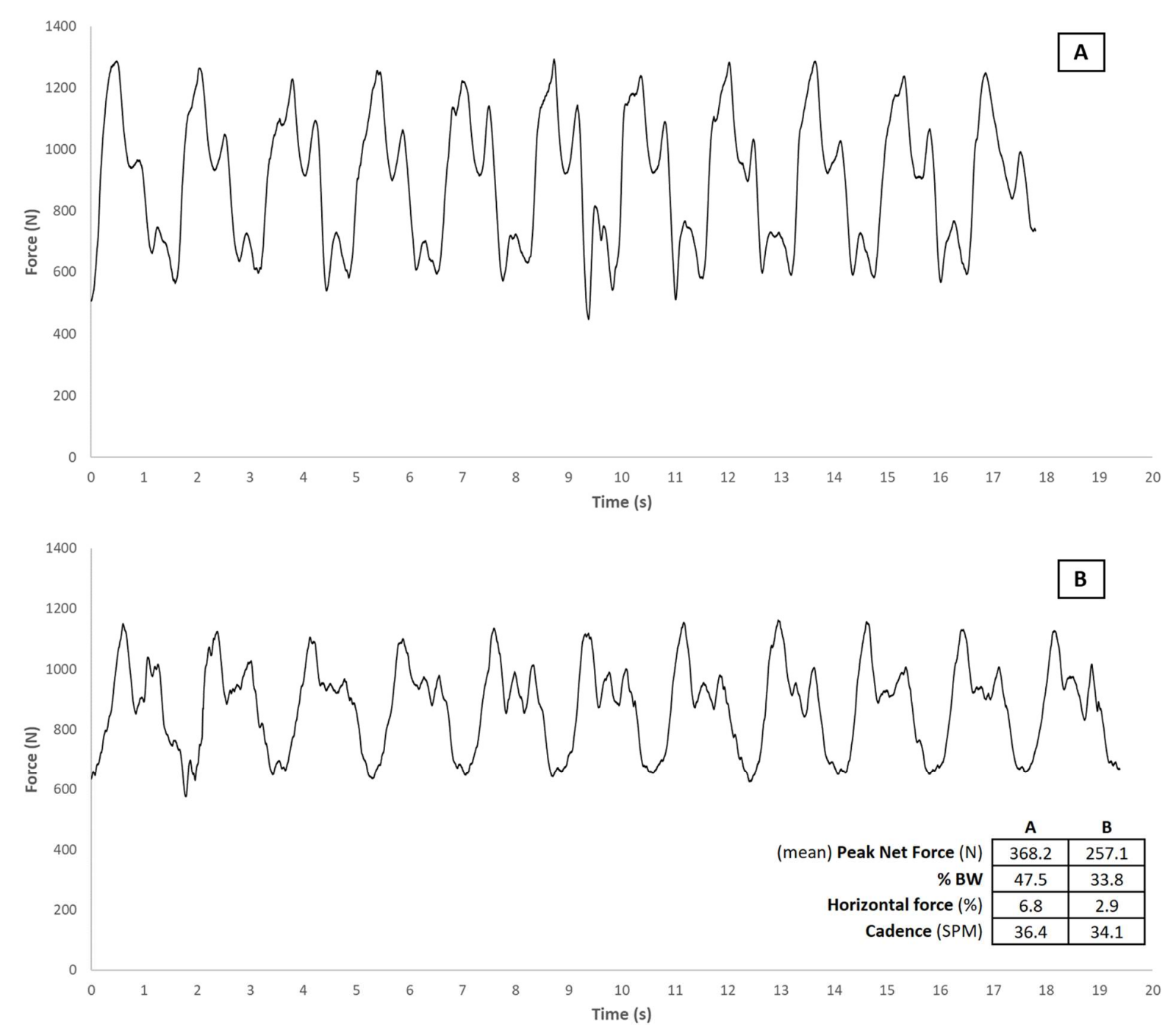

Figure 7. Representative force-time curves from two distinct movement strategies used by novice older adults to perform a two-handed hardstyle kettlebell swing.

\section{Discussion}

Knowledge of GRF and other kinetic variables enables healthcare providers to make informed decisions about the potential benefits and risks of an exercise. A properly designed resistance training program for older adults, includes multi-joint exercises such as the kettlebell swing and kettlebell deadlift, is individualised, periodised, progressive, and includes appropriate technique instruction ${ }^{(16)}$. A review ${ }^{(13)}$ was unable to identify descriptive data of kettlebell exercises from older adults for any of these variables. Results of the present study allow healthcare providers to make a more informed decision about whether, and how to use the kettlebell swing as a therapeutic exercise for older adults.

\section{Ground reaction force}

It was unsurprising that peak net GRF was significantly higher for swings than deadlifts. Force is a product of mass and acceleration and increases with speed in all environmental conditions ${ }^{(33)}$. Peak net ground reaction was $5 \%$ higher during swings with an $8 \mathrm{~kg}$ kettlebell than deadlifts with $32 \mathrm{~kg}$, and 35\% higher than deadlifts with $16 \mathrm{~kg}$. If GRF is the desired therapeutic stimulus, an $8 \mathrm{~kg}$ kettlebell swing could be a better option than a heavier deadlift. Other factors such as reduced cost, ease of storage and transport, and availability in a variety of general-purpose stores, could make 
use of lighter kettlebells for the swing less intimidating and more attractive than the heavier kettlebells that would be required for the deadlift.

Ground reaction force during a proficient swing with an $8 \mathrm{~kg}$ kettlebell can exceed $2 \mathrm{x}$ body mass ${ }^{(19)}$. For the novice older adults, net peak force during an $8 \mathrm{~kg}$ kettlebell swing was 3.9 (1.0) N.kg-1, compared to $8.85 \mathrm{~N}^{-\mathrm{kg}^{-1}}$ for the younger instructor. Whether force of this magnitude can be attained by older adults using kettlebells of this mass remains to be seen, but it is possible, and highlights opportunities for therapeutic exercise in this population. Lower limb strengthening for example, is recommend for management of a host of chronic diseases including symptomatic knee osteoarthritis ${ }^{(34,35)}$. During the kettlebell swing, knee flexion is limited ${ }^{(18)}$ and there are no large ground contact impacts, both mechanisms which are commonly reported to irritate symptomatic arthritic knees. At a cadence of 40 swings per minute, a training load volume of $1,600 \mathrm{~kg}$ can be achieved in as little as five minutes. Safe, easily achievable, and readily scalable, the swing could be an effective and efficient option where time, motivation or desire might be limited. Ground reaction force relative to bodyweight during an $8 \mathrm{~kg}$ swing is comparable to a bodyweight squat performed at a medium to fast pace ${ }^{(33)}$, but the number of bodyweight squats a healthcare provider might prescribe for an older adult, is likely to be far less than the number of swings that could be performed in the same period of time. This may have significant implications for the prescription of training load volume.

More than half of the female participants voluntarily swung a kettlebell heavier than the intended $12 \mathrm{~kg}$ maximum. It was also evident that some of the males had capacity to swing heavier than $16 \mathrm{~kg}$. As these participants were all novices with respect to kettlebell training, this was very encouraging to the potential feasibility of kettlebell swings in this population. Whether there is any physical benefit from using heavier weights has yet to be determined, particularly as effort increases disproportionately to kettlebell weight, and change in GRF is small ${ }^{(19)}$. If the clinical benefits can be gained with a lighter rather than heavier weight, it appears the potential risks of swinging a heavier bell could quickly outweigh the reward. To minimise the risk of injury, it seems reasonable that $12-16 \mathrm{~kg}$ would be "sufficient" for most older adults, with other program variables available to alter the physiological demand, such as the work:rest ratio, altering technique and cadence, and option to use one-arm instead of two.

Males have a higher volume of lean muscle mass than females ${ }^{(36-38)}$, so it was anticipated that peak force would be higher for males. This was true for deadlifts but not for swings, which was surprising. Although the difference in peak force for the deadlift was statistically significant for only three of the nine kettlebells up to $24 \mathrm{~kg}$, there was a consistent moderate effect size with an almost $70 \%$ mean probability of superiority of peak force being higher for males. There was a sex effect for deadlifts, however the lack of such significance for swings is currently unclear.

There was a very large mean effect size $(\delta=3.06)$ in peak force between the older adults in this study and data reported from an instructor ${ }^{(19)}$. For older adults, the average peak force during swings was almost half that of the instructor $(52.1 \%)$, with a mean difference of $4.2 \mathrm{~N} . \mathrm{kg}^{-1}$, highlighting scope for potential improvement from training. Age has previously been shown to have no effect on peak GRF during lifting ${ }^{(39,40)}$, but moderate differences between sex have been observed during Sit-To-Stand tasks in community dwelling older adults (males $>$ females) ${ }^{(10)}$. In the absence of sex-specific health or medical conditions, these results suggest that choice of kettlebell weight should be influenced by bodyweight, strength and/or stature rather than sex.

Novice starting weights for the kettlebell swing are commonly based upon recommendations which are not specific to the swing or older adults ${ }^{(12)}$. Researchers have largely followed these recommendations, however, some investigators have used weights as low as $3 \mathrm{~kg}{ }^{(41-45)}$, heavier weights up to $48 \mathrm{~kg}{ }^{(25,28,46-51)}$, or a percentage of bodyweight e.g. $10-20 \%{ }^{(52,53)}$. Results from this study suggest that healthy novice females, regardless of age and training status, may be able to perform swings safely a with $12-14 \mathrm{~kg}$ if they feel comfortable doing so. 


\section{Forward force}

"Street wisdom" (20) suggests that most of the applied force is in the forward horizontal direction. This belief has influenced training practices to include visualising the bell being projected forward during the propulsion phase, and forcibly snapping the knees into full extension. A recent kinetic analysis of a proficient hardstyle swing, revealed horizontal forward force to be approximately $10-15 \%$ of the magnitude of vertical force, with kettlebell weights from $8 \mathrm{~kg}$ to $32 \mathrm{~kg}{ }^{(19)}$. One of the most striking findings from this study, was that only around $5 \%$ of the ground reaction of a swing was directly horizontally forward. Mean forward force increased from just $3.8 \%$ with $8 \mathrm{~kg}$ to $7.1 \%$ with 16 $\mathrm{kg}$. A small proportion of forward force was expected, however, a mean of $5.5 \%$ with few swings exceeding $10 \%$ was surprisingly low.

There was a very large $(\delta=2.05)$ average effect size in the magnitude of forward force between older adults and instructor ${ }^{(19)}$. Although the absolute mean difference was less than $5 \%$, the relative difference was just over half $(55.1 \%)$. In some cases, horizontal force at peak ground reaction was zero, and in a few instances, negative, albeit negligible in magnitude i.e., indicating that the kettlebell was in effect being pulled backward rather than projected forward at the point of peak effort. This is an interesting biomechanical scenario given the kettlebell's anteroposterior arc of motion and the street wisdom regarding forward force. Tsatsouline describes the motion of the lower limbs during a kettlebell swing as akin to a standing vertical jump ${ }^{12)}$. Extending the knees as rapidly as possible with minimal force applied to the ground, is likely counterproductive for achieving optimal performance during a kettlebell swing. For older adults with painful arthritic knees, forcibly extending the joints may exacerbate unwanted symptoms.

\section{Rate of force development}

Data from a proficient swing showed a strong negative correlation $(r=-0.82)$ in RFD with kettlebell weight ${ }^{(19)}$, so it was surprising to find a neutral correlation among the novice older adults in this study $(r=0.03)$. The effect size between the older adults in this study and instructor was large $(\delta=1.47)$, with a mean difference of $17.0 \mathrm{~N} \cdot \mathrm{s}^{-1} \cdot \mathrm{kg}^{-1}$; almost half that of the instructor (54.2\%). With large variation within the group, it is interesting to consider the outliers. One male participant in the current study, who was still engaged in active employment, recorded a higher RFD than the instructor with the $12 \mathrm{~kg}$ kettlebell $(\delta=0.25)$. The discrepancy in this older male participant's RFD values and that of the other older adults in the present study is interesting and may suggest that there exists the potential for some individuals to maintain high levels of RFD into older age. Results from strength and power training in older adults (54) indicate that it is feasible that kettlebell swings might increase RFD. Combined with large improvements in dynamic single leg balance ${ }^{(55)}$ and postural reaction time ${ }^{(56)}$, kettlebell training may mitigate age-related changes in RFD ${ }^{(57)}$ and reduce falls risk. Whether swings might provide superior clinical benefit in this regard to a more basic deadlift alone remains to be seen.

\section{Swing cadence}

A swing cadence significantly lower than 40 SPM was expected. There was a very large $(\delta=2.54)$ average effect size between older adults and instructor ${ }^{(19)}$, with the older adults performing swings on average 6 SPM slower. Females however, having a cadence almost 2 SPM higher than males was surprising. With kettlebell proficient females of comparable height performing swings at 40 SPM ${ }^{(58)}$, there is currently insufficient data to account for the effect of sex with factors such as height and upper limb length i.e. a taller person with longer arms will displace the kettlebell a greater distance. It was encouraging to see that cadence remained relatively consistent throughout the group, indicating that the pre-selected weights were not 'too heavy'. In current practice, it is unlikely that insufficiently physically active females over 60 years of age would be asked to swing a 12-14 kg kettlebell, or men over 60 years asked to swing $16 \mathrm{~kg}$. These data could be used to challenge common practice regarding weight selection for older adults. 


\section{Force-time profile}

The representative FTCs are more consistent with those of Mache and Hsieh ${ }^{(52)}$ and Lake and Lauder (21) than a proficient swing ${ }^{(19)}$. Our observations support the findings of Back and colleagues ${ }^{(18)}$ with one or both phases of 'lift' and 'float' frequently absent. Observations of technique and deviations from "ideal" could be correlated with changes in the corresponding FTC. A common strategy for some older adults was to actively flex the shoulders to lift the bell upward rather than swing it, typically corresponding with a double-peak FTC. A second smaller force peak seen in a proficient swing ${ }^{(19)}$ was likely absent if the person was observed to control the bell's decent from mid-swing, instead of allowing it to drop. Practically, this strategy shifts emphasis of the mechanical load of deceleration from the hips and lower limbs to the trunk and upper limbs.

Less visually apparent was the squatting motion previously observed in novices ${ }^{(18)}$. This relative lack of a squatting motion observed in the older participants in the current study was attributed to the pre-test drills encouraging the 'hiphinge' pattern performed by the instructor with the participants in the current study. A wider, multi-peaked FTC and slower cadence was consistent with a more pronounced simultaneous movement pattern. Whether differences in swing pattern are clinically meaningful has not been investigated. It is possible that technique may influence performance improvement and rehabilitation conditions. An 'ideal' swing may not be achievable for some, and some betweenparticipant variability in technique could be beneficial.

As anticipated, none of the participants were able to perform an ideal hardstyle swing consistently for all repetitions with all loads. There were, however, many examples where it was evident in the FTC, that participants had performed one or more swings within the set, which were approaching ideal (Supp. file A: M4, M6, M7, M9, M12, M13, M15, M16, M17, F1, F3, F5, F9, F11-15, F17, F18). Most participants had a force profile suggestive of a swing rather than lift, which was surprising and very encouraging. In addition to common drills, use of real-time biofeedback where available, and slow-motion video analysis, are likely to be beneficial for novices learning how to perform a hardstyle swing ${ }^{(59)}$.

The hardstyle swing may be considered to be a movement pattern that has some unusual characteristics and that may be challenging to learn for some individuals, especially older adults. While a range of hip hinge and ballistic drills can be effective for improving technique, some people can find them confusing and complicated to follow, a situation which can be compounded with multiple drills. Many of the participants were able to quickly improve their technique by simply focusing on increasing the swing cadence. Swing cadence could be a useful measure to determine an appropriate upper limit for the most appropriate kettlebell weight, particularly in combination with an increasing rate of observed or reported effort. Achieving a consistent cadence of 40 SPM with a comfortable (lighter) kettlebell appears to be an appropriate strategy for the novice individual learning the swing. Health professionals should note that the cardiovascular demand of kettlebell swings may be higher than walking ${ }^{(29)}$ and should anticipate a higher heart rate and cardiovascular response ${ }^{(60,61)}$ and program for the individual accordingly.

Our suggestion that changes in a FTC might be used to determine an optimal training weight ${ }^{(19)}$, assumes a proficient swing and availability of real time biofeedback. So how should optimal kettlebell weight be determined for novice older adults? For some participants, increasing bell weight appeared to improve their technique, but for others, additional weight had a detrimental effect. It remains to be seen whether monitoring mechanical demands to inform weight selection provides any benefit beyond the existing pragmatic hardstyle approach. Optimising starting weights and progression during the initial and early stages of learning a hardstyle swing is where input from an appropriate experienced provider is likely to be most beneficial.

The influence of confounding variables such as technique, age, and training history on resultant force are unclear. Pragmatically however, the combined testing loads for the deadlift session were $1,728 \mathrm{~kg}$ and $2,448 \mathrm{~kg}$ for females and males, respectively. With many older adults routinely under-dosed in resistance training programs ${ }^{(62)}$, these data might help change that trend. Acknowledging that clinical reasoning should influence instruction around speed, 
movement, treatment goals and individual preferences ${ }^{(33)}$, in the absence of identifiable risks and within the constraints of a person's unique health history, clinical needs, and the desire (or not) to engage in a program of resistance training, these findings might encourage providers to broaden their perceived scope of therapeutic load.

Limitations. Results from predominantly insufficiently physically active older adults may not be generalisable to all older adults, or those for whom a diagnosed health or medical condition presents an increased risk of harm from resistance exercise, or which effects their ability to perform the exercise. Ground reaction force and technique among novices is likely to quickly improve with practice and appropriate instruction, therefore, these data may not represent older adults who have undergone a period of kettlebell exercise practice and training. Rate of force development should be interpreted with caution. Specifically, in the absence of concurrent video analysis, calculation of RFD from force-plate data of novices where the propulsive phase is not clear, is subject to interpretation and reduces reliability. Ground reaction data from hardstyle swings cannot be generalised to the double knee-bend swing (kettlebell Sport) or overhead (American) swing which are kinematically different ${ }^{(28,63)}$.

\section{Conclusions}

Results of this exploratory profiling study suggest that the prescription of exercise intensity (weight) for kettlebell swings and kettlebell deadlifts for older adults should not be determined by sex. All older females and males comfortably performed multiple deadlifts up to $24 \mathrm{~kg}$ and $32 \mathrm{~kg}$, respectively. Healthcare providers are encouraged to explore the potential of their older patients/clients in this regard. A two-handed hardstyle kettlebell swing with $8 \mathrm{~kg}$ resulted in greater ground reaction force than a $32 \mathrm{~kg}$ deadlift. Lighter weight bells may be a more cost-effective, convenient, and appealing option for therapists and patients than heavier alternatives. Where GRF is the clinical measure of interest, an $8 \mathrm{~kg}$ swing has the potential to provide similar acute kinetic demands as deadlifts with a much heavier bell, and likely to have a greater influence on increasing lower limb RFD. Further research is warranted to investigate the long-term effects of using only dynamic movements such as the swing compared with slower, heavier movements such as the deadlift. A target cadence of 40 SPM is likely to positively influence RFD and GRF in novices, but further research is required to establish the influence of hardstyle technique on clinical outcomes of interest in older adults.

\section{Acknowledgements}

The authors would like to acknowledge Mr Benjamin Hindle for his support in the calculation of rate of force development, and Mrs Evelyne Rathbone for her direction with statistical analysis.

\section{Funding}

This study was supported by an Australian Government Research Training Program Scholarship and will contribute towards a Higher Degree by Research Degree (Doctor of Philosophy).

\section{Contributions}

NM recruited the participants and conducted the study, curated and analysed the data, interpreted the results, conducted the formal analysis, and wrote the original draft. JK, BS and WH supported with ongoing consultation. JK and WH reviewed and provided revisions to earlier versions of the manuscript. All authors read and approved the final manuscript.

\section{Ethics declarations}

Ethics approval and consent to participate

Not applicable

\section{Consent for publication}

Not applicable 


\section{Competing interests}

Neil J. Meigh is a Physiotherapist and hardstyle kettlebell instructor, with an online presence as The Kettlebell Physio. Justin W.L. Keogh is an academic editor for PeerJ. BS and WH declare that they have no competing interests.

\section{Rights and permissions}

Open Access This article is distributed under the terms of the Creative Commons Attribution 4.0 International License (http://creativecommons.org/licenses/by/4.0/), which permits unrestricted use, distribution, and reproduction in any medium, provided you give appropriate credit to the original author(s) and the source, provide a link to the Creative Commons license, and indicate if changes were made. The Creative Commons Public Domain Dedication waiver (http://creativecommons.org/publicdomain/zero/1.0/) applies to the data made available in this article, unless otherwise stated.

\section{References}

1. Chen HT, Wu HJ, Chen YJ, Ho SY, Chung YC. Effects of 8-week kettlebell training on body composition, muscle strength, pulmonary function, and chronic low-grade inflammation in elderly women with sarcopenia. Exp Gerontol. 2018;112:112-8.

2. Marcelino C. Effects of kettlebell training on functional performance, postural stability and isokinetic strength of lower limbs in individuals with Parkinson's disease [masters]. Brazil: Univeristy of Brazil. 2017.

3. Otto WH, 3rd, Coburn JW, Brown LE, Spiering BA. Effects of weightlifting vs. kettlebell training on vertical jump, strength, and body composition. J Strength Cond Res. 2012;26(5):1199-202.

4. Soukkio P, Suikkanen S, Kääriä S, Kautiainen H, Sipilä S, Kukkonen-Harjula K, et al. Effects of 12-month home-based physiotherapy on duration of living at home and functional capacity among older persons with signs of frailty or with a recent hip fracture - protocol of a randomized controlled trial (HIPFRA study). BMC Geriatr. 2018;18(1):232-.

5. Khan KM, Scott A. Mechanotherapy: how physical therapists' prescription of exercise promotes tissue repair. Br J Sports Med. 2009;43(4):247.

6. Smidt N, de Vet HCW, Bouter LM, Dekker J. Effectiveness of exercise therapy: A best-evidence summary of systematic reviews. Aust J Physiother. 2005;51(2):71-85.

7. Teichtahl AJ, Wluka AE, Wijethilake P, Wang Y, Ghasem-Zadeh A, Cicuttini FM. Wolff's law in action: a mechanism for early knee osteoarthritis. Arthritis research \& therapy. 2015;17(1):207.

8. Hester G, Ha P, Dalton B, VanDusseldorp T, Olmos A, Stratton M, et al. Rate of force development as a predictor of mobility in older adults. J Geriatr Phys Ther. 2019.

9. LaRoche DP, Millett ED, Kralian RJ. Low strength is related to diminished ground reaction forces and walking performance in older women. Gait Posture. 2011;33(4):668-72.

10. Tsuji T, Tsunoda K, Mitsuishi Y, Okura T. Ground reaction force in sit-to-stand movement reflects lower limb muscle strength and power in community-dwelling older adults. International Journal of Gerontology. 2015;9(2):111-8.

11. Kera T, Kawai H, Takahashi J, Hirano H, Watanabe Y, Fujiwara Y, et al. Association between ground reaction force in sit-to-stand motion and falls in community-dwelling older Japanese individuals. Arch Gerontol Geriatr. 2020;91:104221.

12. Tsatsouline P. Enter The Kettlebell: strength secret of the soviet supermen. St. Paul, MN, USA: Dragon Door Publications; 2006.

13. Meigh NJ, Keogh JWL, Schram B, Hing WA. Kettlebell training in clinical practice: a scoping review. BMC Sports Science, Medicine and Rehabilitation. 2019;11(1):19.

14. Borde R, Hortobagyi T, Granacher U. Dose-response relationships of resistance training in healthy old adults: a systematic review and meta-analysis. Sports Med. 2015;45(12):1693-720.

15. Lopez P, Pinto RS, Radaelli R, Rech A, Grazioli R, Izquierdo M, et al. Benefits of resistance training in physically frail elderly: a systematic review. Aging Clin Exp Res. 2017:1-11.

16. Fragala MS, Cadore EL, Dorgo S, Izquierdo M, Kraemer WJ, Peterson MD, et al. Resistance training for older adults. J Strength Cond Res. 2019;33(8):2019-52.

17. Tsatsouline P. RKC Instructor Manual. 1st ed. St. Paul, MN, USA: Dragon Door Publications Inc.; 2013.128 p.

18. Back C-Y, Joo J-Y, Kim Y-K. Kinematic comparisons of kettlebell two-arm swings by skill level. Korean Journal of Sport Biomechanics. 2016;26(1):39-50. 
19. Meigh NJ, Hing WA, Schram B, Keogh JWL. Mechanical demands of the two-handed hardstyle kettlebell swing performed by an RKC-certified Instructor. bioRxiv. 2021:2021.05.13.444085.

20. McGill SM, Marshall LW. Kettlebell swing, snatch, and bottoms-up carry: back and hip muscle activation, motion, and low back loads. J Strength Cond Res. 2012;26(1):16-27.

21. Lake JP, Lauder MA. Mechanical demands of kettlebell swing exercise. J Strength Cond Res. 2012;26(12):320916.

22. Lake JP, Hetzler BS, Lauder MA. Magnitude and relative distribution of kettlebell snatch force-time characteristics. J Strength Cond Res. 2014;28(11):3063-72.

23. Ross JA, Keogh JW, Wilson CJ, Lorenzen C. External kinetics of the kettlebell snatch in amateur lifters. PeerJ. 2017;5:e3111.

24. Levine NA, Hasan MB, Avalos MA, Lee S, Rigby BR, Kwon Y-H. Effects of kettlebell mass on lower-body joint kinetics during a kettlebell swing exercise. Sports Biomech. 2020:1-14.

25. Bullock GS, Schmitt AC, Shutt JM, Cook G, Butler RJ. Kinematic and kinetic variables differ between kettlebell swing styles. Int J Sports Phys Ther. 2017;12(3):324-32.

26. ESSA. Adult pre-exercise screening system tool (v1): ESSA; 2011 [Available from: http://ow.ly/Se9y50E8S9B.

27. Thomas JF. Comparison of interval kettlebell exercise and cycle ergometry: Effectiveness as a stimulus for cardiorespiratory fitness: Southeastern Louisiana University; 2014.

28. Del Monte MJ, Opar DA, Timmins RG, Ross JA, Keogh JW, Lorenzen C. Hamstring myoelectrical activity during three different kettlebell swing exercises. The Journal of Strength \& Conditioning Research. 2020;34(7):1953-8.

29. Thomas JF, Larson KL, Hollander DB, Kraemer RR. Comparison of two-hand kettlebell exercise and graded treadmill walking: effectiveness as a stimulus for cardiorespiratory fitness. J Strength Cond Res. 2014;28(4):9981006.

30. Lenhard W, Lenhard A. Calculation of effect sizes Dettelbach (Germany): Psychometrica.2016 [Available from: http://www.psychometrica.de/effect size.html.

31. Magnusson K. Interpreting Cohen's $\bar{d}$ effect size: an interactive visualization (Version 2.5.0) [Web App]. R Psychologist.; 2021 [Available from: https://rpsychologist.com/cohend/.

32. Hopkins WG, Marshall SW, Batterham AM, Hanin J. Progressive statistics for studies in sports medicine and exercise science. Med Sci Sports Exerc. 2009;41(1):3-13.

33. Heywood S, McClelland J, Geigle P, Rahmann A, Villalta E, Mentiplay B, et al. Force during functional exercises on land and in water in older adults with and without knee osteoarthritis: Implications for rehabilitation. The Knee. 2019;26(1):61-72.

34. Turner MN, Hernandez DO, Cade W, Emerson CP, Reynolds JM, Best TM. The role of resistance training dosing on pain and physical function in individuals with knee osteoarthritis: a systematic review. Sports health. 2019;12(2):200-6.

35. Goh S-L, Persson MSM, Stocks J, Hou Y, Welton NJ, Lin J, et al. Relative efficacy of different exercises for pain, function, performance and quality of life in knee and hip osteoarthritis: systematic review and network meta-analysis. Sports medicine (Auckland). 2019;49(5):743-61.

36. Pasco JA, Stuart AL, Holloway-Kew KL, Tembo MC, Sui SX, Anderson KB, et al. Lower-limb muscle strength: normative data from an observational population-based study. BMC Musculoskeletal Disorders. 2020;21(1):89.

37. Janssen I, Baumgartner RN, Ross R, Rosenberg IH, Roubenoff R. Skeletal muscle cutpoints associated with elevated physical disability risk in older men and women. Am J Epidemiol. 2004;159(4):413-21.

38. Aguado-Henche S, Carrascosa-Sánchez J, Cristóbal-Aguado S, Clemente de Arriba C. Normative values for body compartments of sedentary white people. MOJ Anat Physiol. 2017;4(1):217-25.

39. Shin G, Nance M, Mirka G. Differences in trunk kinematics and ground reaction forces between older and younger adults during lifting. International Journal of Industrial Ergonomics. 2006;36:767-72.

40. Lim JY, Yi Y, Jung SW, Park D-S. Comparison of vertical ground reaction forces between female elderly and young adults during sit-to-stand and gait using the Nintendo Wii Balance Board. Physical Therapy Rehabilitation Science. 2018;7(4):179-85.

41. Lim J, Kim M, Kim J, Hong J, Lee D, Yu J. Core and lower limb activations of the two-handed and singlehanded kettlebell exercises. Research Journal of Pharmacy and Technology. 2018;11(3):1101-6.

42. Rajala BA, Jensen RL, editors. EMG of lower limb muscles during kettlebell exercises. ISBS-Conference Proceedings Archive; 2015.

43. Zin MAM, Rambely AS, Ariff NM, editors. A preliminary study on effects of increment of loads to lower extremity joints during kettlebell swing activity. AIP Conference Proceedings; 2018: AIP Publishing LLC. 
44. Duncan M, Gibbard R, Raymond L, Mundy P. The effect of kettlebell swing load and cadence on physiological, perceptual and mechanical variables. Sports. 2015;3(3):202-8.

45. Fortner HA, Salgado JM, Holmstrup AM, Holmstrup ME. Cardiovascular and metabolic demands of the kettlebell swing using tabata interval versus a traditional resistance protocol. International Journal of Exercise Science. 2014;7(3):179-85.

46. Falatic JA, Plato PA, Holder C, Finch D, Han K, Cisar CJ. Effects of kettlebell training on aerobic capacity. J Strength Cond Res. 2015;29(7):1943-7.

47. Holmstrup ME, Jensen BT, Evans WS, Marshall EC. Eight weeks of kettlebell swing training does not improve sprint performance in recreationally active females. International Journal of Exercise Science. 2016;9(3):437-44.

48. Oikarinen S. American kettlebell swing and the risk of lumbar spine injury. 2016.

49. Lake JP, Lauder MA. Kettlebell swing training improves maximal and explosive strength. J Strength Cond Res. 2012;26(8):2228-33.

50. Santillo N. The comparative effect of recovery interventions on blood lactate removal post-high intensity kettlebell training session: The William Paterson University of New Jersey; 2016.

51. Smith CE, Lyons B, Hannon JC. A pilot study involving the effect of two different complex training protocols on lower body power. Human Movement. 2014;15(3).

52. Mache MA, Hsieh C, editors. A temporal and kinetic comparison of the kettlebell swing and maximal vertical jump. ISBS-Conference Proceedings Archive; 2016.

53. Ros T. Comparison of kettlebell jump squats vs kettlebell swings as postactivation potentiation on vertical jumps: California State University, Fullerton; 2016.

54. Caserotti P, Aagaard P, Buttrup Larsen J, Puggaard L. Explosive heavy-resistance training in old and very old adults: changes in rapid muscle force, strength and power. Scand J Med Sci Sports. 2008;18(6):773-82.

55. Beltz N, Erbes D, Porcari JP, Martinez R, Doberstein S, Foster C. Effects of kettlebell training on aerobic capacity, muscular strength, balance, flexibility, and body composition. . Journal of Fitness Research. 2013;2(2):4-13.

56. Manocchia P, Spierer DK, Lufkin AK, Minichiello J, Castro J. Transference of kettlebell training to strength, power, and endurance. J Strength Cond Res. 2013;27(2):477-84.

57. Maffiuletti NA, Aagaard P, Blazevich AJ, Folland J, Tillin N, Duchateau J. Rate of force development: physiological and methodological considerations. Eur J Appl Physiol. 2016;116(6):1091-116.

58. Wesley C. Effects of kettlebell mass \& swing cadence on heart rate, blood lactate and ratings of perceived exertion during an interval kettlebell swing protocol. ProQuest Dissertations Publishing; 2013.

59. Beerse M, Bigelow KE, Barrios JA. The patterning of local variability during the acquisition of a novel whole-body continuous motor skill in young adults. Exp Brain Res. 2020.

60. Schnettler C, Porcari J, Foster C, Anders M. Physiologic responses to a kettlebell workout. University of Wisconsin-La Crosse.: University of Wisconsin-La Crosse; 2009.

61. Wong A, Nordvall M, Walters-Edwards M, Lastova K, Francavillo G, Tripken J, et al. Cardiac autonomic and blood pressure responses to an acute bout of kettlebell exercise. Med Sci Sports Exerc. 2017;49(5):721-.

62. APTA. Don't prescribe under-dosed strength training programs for older adults. Instead, match the frequency, intensity and duration of exercise to the individual's abilities and goals. 2014 [cited 2018. Available from: http://ow.ly/O9C350E8Sb7.

63. Mitchell J, Johnson W, Riemann B, Krajewski K, Coates C, editors. Biomechanical loading of the American kettlebell swing. ASME International Mechanical Engineering Congress and Exposition; 2015; Houston, Texas, USA: American Society of Mechanical Engineers. 